\title{
Predicting cardiometabolic risk: waist-to-height ratio or BMI. A meta-analysis
}

This article was published in the following Dove Press journal:

Diabetes, Metabolic Syndrome and Obesity: Targets and Therapy

23 October 2013

Number of times this article has been viewed

\section{Savvas C Savva' \\ Demetris Lamnisos ${ }^{2}$ \\ Anthony G Kafatos ${ }^{3}$}

'Research and Education Institute of Child Health, Strovolos, Cyprus; ${ }^{2}$ Department of Nursing, School of Health Sciences, Cyprus University of Technology, Limassol, Cyprus; ${ }^{3}$ Preventive Medicine and Nutrition Unit, School of Medicine, University of Crete, Heraklion, Crete, Greece

Correspondence: Savvas C Savva

138, Limassol Ave, \#205,

2015 Strovolos, Cyprus

Tel +357225 I 0310

$\mathrm{Fax}+35722510903$

Email sc.savvas@cytanet.com.cy
Background and objectives: The identification of increased cardiometabolic risk among asymptomatic individuals remains a huge challenge. The aim of this meta-analysis was to compare the association of body mass index (BMI), which is an index of general obesity, and waist-to-height ratio (WHtR), an index of abdominal obesity, with cardiometabolic risk in cross-sectional and prospective studies.

Methods: PubMed and Embase databases were searched for cross-sectional or prospective studies that evaluated the association of both BMI and WHtR with several cardiometabolic outcomes. The strength of relative risk (RR) with $95 \%$ confidence interval (CI) was calculated using the optimal cutoffs of BMI and WHtR in cross-sectional studies, while any available cutoff was used in prospective studies. The pooled estimate of the ratio of RRs ( $\mathrm{rRR}\left[=\mathrm{RR}_{\mathrm{BMI}} /\right.$ $\left.\mathrm{RR}_{\mathrm{wHtR}}\right]$ ) with $95 \%$ CIs was used to compare the association of WHtR and BMI with cardiometabolic risk. Meta-regression was used to identify possible sources of heterogeneity between the studies.

Results: Twenty-four cross-sectional studies and ten prospective studies with a total number of 512,809 participants were identified as suitable for the purpose of this meta-analysis. WHtR was found to have a stronger association than BMI with diabetes mellitus (rRR: $0.71,95 \% \mathrm{CI}$ : 0.59-0.84) and metabolic syndrome (rRR: 0.92, 95\% CI: 0.89-0.96) in cross-sectional studies. Also in prospective studies, WHtR appears to be superior to BMI in detecting several outcomes, including incident cardiovascular disease, cardiovascular disease mortality, and all-cause mortality. The usefulness of WHtR appears to be better in Asian than in non-Asian populations. BMI was not superior to WHtR in any of the outcomes that were evaluated. However, the results of the utilized approach should be interpreted cautiously because of a substantial heterogeneity between the results of the studies. Meta-regression analysis was performed to explain this heterogeneity, but none of the evaluated factors, ie, sex, origin (Asians, non-Asians), and optimal BMI or WHtR cutoffs were significantly related with rRR.

Conclusion: The results of this meta-analysis support the use of WHtR in identifying adults at increased cardiometabolic risk. However, further evidence is warranted because of a substantial heterogeneity between the studies.

Keywords: body mass index, waist-to-height ratio, meta-analysis, cardiometabolic

\section{Introduction}

The use of different combinations of anthropometric indices has been shown to produce substantially different proportions of subjects at increased health risks. ${ }^{1}$ Body mass index (BMI), as an index of general adiposity, and several indices of abdominal obesity, such as waist circumference (WC) and waist-to-hip ratio (WHR), are associated 
with increased cardiometabolic risk and risk of death. Several meta-analyses have failed to prove substantial superiority of abdominal obesity indices over BMI or between the two aforementioned abdominal obesity indices. ${ }^{2-4}$

Since the mid-1990s, waist-to-height ratio (WHtR) has emerged as a promising index for identification of subjects at increased cardiometabolic risk in both adults ${ }^{5-7}$ and children. ${ }^{8,9}$ A huge number of studies have been undertaken since then in order to evaluate the ability of this index in comparison to BMI and other indices to identify healthy humans at increased cardiometabolic risk. It has been suggested that WHtR has several advantages compared to BMI, and even to WC and WHR, as a simple and rapid screening tool, including its ability to identify health risks in both males and females, in different ethnic groups, and in all age groups, including adults and children. ${ }^{10}$ Moreover, it has been proposed that a cutoff value of 0.5 for both men and women and individuals of Caucasian, Asian, and Central American origin can be used for the prediction of cardiometabolic risk. This value was the mean value of the suggested boundary values regarding several cardiovascular disease (CVD) risk factors. ${ }^{11}$ This cutoff has been used to support the simple public health message "keep your waist circumference to less than half your height." 11

Several meta-analyses have aimed to put together the results from studies highlighting the usefulness of WHtR compared to BMI and other body fatness indices to identify cardiometabolic risk in healthy adults ${ }^{12-15}$ and children. ${ }^{16}$ Barzi et al concluded that no single index among BMI, WHtR, WC, and WHR is superior than any other in detecting dyslipidemia in both Asian and non-Asian populations. ${ }^{13}$ In the meta-analysis of van Dijk et al, ${ }^{15} \mathrm{WC}$ was proposed as superior in detecting single CVD risk factors compared to BMI, WHtR, and WHR, but this meta-analysis used only correlation coefficients for their conclusions. Kodama et al showed that WHtR had a stronger association with incident diabetes than BMI and WHR. ${ }^{14}$ Ashwell et al showed that WHtR had a better discriminatory power than BMI and WC in detecting several cardiometabolic risk factors. ${ }^{12}$ This latter meta-analysis used pooled area-under-the-curve values but included both cross-sectional and prospective studies in the same models.

The aim of the present meta-analysis, therefore, was to compare the ability of WHtR and BMI to detect multiple cardiometabolic risks and mortality, both cross-sectionally and prospectively, using reported optimal cutoffs for these indices.

\section{Methods}

\section{Data sources and search strategy}

A literature search was performed using Pubmed and Embase databases through May 9, 2013 using the terms ("waist-toheight ratio" OR "waist/height ratio" OR "stature-to-height ratio" OR "stature/height ratio" OR "WHtR" OR "WSR") AND ("body mass index" OR "BMI"). Only original full-text studies written in English were selected for analysis. Conference abstracts were excluded since presented information was limited for data extraction.

\section{Inclusion criteria}

- Adults older than 18 years, irrespective of sex and ethnic background

- Cross-sectional or prospective studies

- Studies reporting associations between at least one of the primary outcomes and both anthropometric indices, ie, exposure measures BMI and WHtR

- For cross-sectional studies, only those reporting optimal BMI and WHtR cutoffs

- Studies from which $2 \times 2$ tables could be retrieved (outcome present/absent, exposure positive/negative).

\section{Exclusion criteria}

- Case-control studies

- Studies evaluating cardiometabolic risk in specific high-risk groups (eg, patients undergoing coronary angiography)

- Studies reporting on single lipid abnormality or single systolic or diastolic hypertension

- Studies with children and/or adolescents.

\section{Primary outcomes}

Primary outcomes for cross-sectional studies were defined as follows:

1. Diabetes mellitus (DM). Any combination of fasting blood glucose $\geq 7.0 \mathrm{mmol} / \mathrm{L}$ ( $\geq 126 \mathrm{mg} / \mathrm{dL})$ or 2-hour post-challenge blood glucose $\geq 11.1 \mathrm{mmol} / \mathrm{L}$ ( $\geq 200 \mathrm{mg} / \mathrm{dL}$ ) or patients with physician diagnosis of diabetes or patients receiving anti-diabetic medication.

2. Elevated blood pressure. Any combination of systolic blood pressure $\geq 130 \mathrm{mmHg}$ and/or diastolic blood pressure $\geq 85 \mathrm{mmHg}$ and/or patients with physician diagnosis of hypertension and/or patients receiving antihypertensive medication.

3. Dyslipidemia. Treatment for dyslipidemia or two or more abnormal serum lipid measurements including 
total cholesterol $\geq 5.2 \mathrm{mmol} / \mathrm{L}(\geq 200 \mathrm{mg} / \mathrm{dL})$, low-density-lipoprotein cholesterol $\geq 3.5 \mathrm{mmol} / \mathrm{L}$ ( $\geq 135 \mathrm{mg} / \mathrm{dL})$, triglycerides $\geq 1.7 \mathrm{mmol} / \mathrm{L}(\geq 150 \mathrm{mg} / \mathrm{dL})$, or high-density-lipoprotein cholesterol $<1.03 \mathrm{mmol} / \mathrm{L}$ $(<40 \mathrm{mg} / \mathrm{dL})$.

4. Metabolic syndrome (MetS). Two or more risk factors according to International Diabetes Federation or American Heart Association criteria when WC was not included in the definition (ie, two or more criteria out of four), or three or more criteria when WC was included in the criteria (ie, three or more criteria out of five).

Regarding prospective studies, primary outcomes were: all-cause mortality; CVD mortality; incident CVD including myocardial infarction and stroke; and incident DM using the same cutoffs as described previously.

\section{Exposure cutoffs selection}

The search of the identified studies revealed that reporting of exposure cutoffs was based on three different methods by the researchers: optimal cutoffs, ie, cutoffs that were chosen in order to maximize sensitivity and specificity of the indices; standard cutoffs, ie, selection of $25 \mathrm{~kg} / \mathrm{m}^{2}$ for non-Asians or $23 \mathrm{~kg} / \mathrm{m}^{2}$ for Asians for BMI cutoffs and of 0.5 for WHtR cutoffs; and cutoffs based on percentiles, ie, data were split in quartiles, quintiles, and so forth. We initially aimed to evaluate the discriminative ability of standard BMI and WHtR cutoffs in detecting cardiometabolic risk. However, this task proved difficult because of the limited number of studies that presented findings in a way that data could be extracted for meta-analysis. Therefore, in cross-sectional studies, we utilized only studies reporting optimal cutoffs. In prospective studies, due to a limited number of studies, we utilized optimal cutoffs or cutoffs based on percentiles. In the latter case, percentile cutoff nearest to "standard" cutoffs were selected.

\section{Data extraction}

Data extracted from each eligible study included first author; year of publication; participants' age, sex, and nationality (which was further classified in Asian and non-Asian groups); study type (cross-sectional, prospective); criteria used for defining primary outcomes; and exposure cutoffs. Moreover, we extracted the numbers of patients and healthy individuals for each primary outcome in relation to exposure measures BMI and WHtR, dichotomized according to reported cutoffs. Those numbers were presented in a $2 \times 2$ table (primary outcome versus exposure) for each outcome and each exposure measure. When precise numbers of patients and healthy individuals depending on exposure measures were not reported in studies presenting optimal exposure cutoffs, we utilized indirect methods for calculating these numbers. Specifically, we used reported sensitivity and specificity rates along with numbers of patients and healthy individuals in order to extract the $2 \times 2$ table (primary outcome versus exposure).

\section{Quality assessment}

Quality of all selected prospective studies was assessed using the Newcastle-Ottawa quality assessment Scale (NOS). ${ }^{17}$ The NOS uses a star rating system to assess quality based on three aspects of the cohort study: selection of study groups (maximum 4 stars); comparability of study groups (maximum 2 stars); and ascertainment of outcome of interest (maximum 3 stars). Therefore, a prospective study may receive a maximum of 9 stars. The NOS is not able to be used in crosssectional studies, therefore a similar approach to the one used by Friedemann et al was used. ${ }^{16}$ This approach considered five elements: 1) representativeness of the study; 2) ascertainment of exposure; 3) selective reporting; 4) incomplete outcome data; and 5) assessment of outcome. Each of these outcomes could receive 1 star, therefore a cross-sectional study might receive a maximum of 5 stars.

\section{Statistical analysis}

Pooled ratio of relative risks (rRR) with 95\% CIs was the principal measure for comparing the strength of BMI versus that of WHtR as a screening tool for the primary outcomes. The pooled rRR was calculated as follows:

$$
\mathrm{rRR}=\mathrm{RR}_{\mathrm{BMI}} / \mathrm{RR}_{\mathrm{wHtR}}
$$

An upper bound of the $95 \%$ CI for rRR less than 1 indicates significant strength in favor of WHtR and a lower bound of $95 \%$ CI greater than 1 indicates significant strength in favor of BMI. In the case that the $95 \%$ CI overlapped with 1 , then the relative strength was in favor of neither of the two exposures. The $95 \%$ CI of rRR for each study was calculated by assuming a normal approximation to

$$
\log (\mathrm{rRR})=\log \left(\mathrm{RR}_{\mathrm{BMI}}\right)-\log \left(\mathrm{RR}_{\mathrm{wHtR}}\right)
$$

and then antilog to construct asymmetric 95\% CI around $\mathrm{rRR}$. The variance of $\log (\mathrm{rRR})$ was approximated by the sum of the variances of $\log \left(R_{R_{B M I}}\right)$ and $\log \left(R_{\mathrm{wHtR}_{\mathrm{R}}}\right)$. In most studies, results were reported separately for men and 
women; therefore, results from these studies were included separately, and thus the term "data units" is used instead of "studies." Meta-analysis of rRR for primary outcomes reported in at least two studies was performed using the DerSimonian and Laird random effect statistical model. ${ }^{18}$ This model takes into account both the between- and withinstudies variability.

Subgroup analysis was also performed by first stratifying the studies according to origin (Asian and non-Asian) and then further stratified according to sex. Quantitative heterogeneity in the results was investigated by the $\mathrm{I}^{2}$ statistic, while the Egger's regression test was used to assess the publication bias in each obesity measure separately. Investigation of possible sources of heterogeneity was performed using meta-regression in outcomes from the cross-sectional studies. In the outcomes from prospective studies, meta-regression was not performed due to the limited number of studies. The $\log (\mathrm{rRR})$ was used as the dependent variable in meta-regression, and participants' sex, origin, optimal BMI or WHtR cutoffs, as well as an interaction term between participants' sex and origin, were used as the covariates in attempts to explain the heterogeneity.

Analyses were performed with the aid of the metafor package ${ }^{19}$ with R statistical software (v 3.0.1; The R Foundation for Statistical Computing, Vienna, Austria). ${ }^{20}$

\section{Results}

\section{Study and participant characteristics}

The search strategy yielded 1,460 studies from the PubMed database and 763 studies from the Embase database. After applying inclusion and exclusion criteria, a total of 34 studies were included in this meta-analysis (Figure 1); 46 data units from 24 cross-sectional studies with optimal BMI and WHtR cutoffs ${ }^{21-44}$ and 18 data units from ten prospective studies. ${ }^{45-54}$ The total number of participants in the crosssectional studies was 221,814 individuals, of which 177,974 were Asians and 43,840 non-Asians. In the cross-sectional studies, there were 6,850 patients with DM, 26,491 patients with dyslipidemia, 20,467 with elevated blood pressure, and 19,014 with MetS. The total number of participants in the prospective studies was 290,995 individuals of which 137,325 were Asians and 153,670 non-Asians. In prospective studies, there were 6,057 patients with incident DM, 4,388 patients with incident CVD, 1,903 with CVD mortality, and 5,642 with all-cause mortality.

In all 34 studies, the total number of participants was 512,809 persons. The age limit in the inclusion criteria was
18 years or older; however, we included two studies in which participants' ages were $>15$ years $^{22}$ or 15 to 74 years. $^{27}$ Furthermore, four of the included studies did not determine range of age but rather provided mean age with standard deviation. ${ }^{25,28,29,34}$

The characteristics of the included studies are presented in Table 1. From cross-sectional studies reporting results based on optimal BMI and WHtR cutoffs, we identified a total of 27 data units from 14 studies reporting associations with DM, ${ }^{21-34} 19$ data units from ten studies with dyslipidemia, ${ }^{21,23-25,27,29,32-35} 34$ data units from 18 studies with elevated blood pressure, ${ }^{21-25,27-32,34-40}$ and 16 data units from eight studies with MetS. ${ }^{23,33,35,38,41-43}$ In prospective studies, we identified ten data units from five studies reporting associations with incident $\mathrm{DM},{ }^{21-44}$ four data units from three studies with incident CVD, ${ }^{50-52}$ four data units from two studies with CVD mortality, ${ }^{53,54}$ and four data units from two studies with all-cause mortality. ${ }^{53,54}$

\section{Exposure measure cutoffs}

The summary of the optimal cutoffs from the crosssectional studies in each of the outcomes is presented in Table 2. From this table, it is obvious that both BMI and WHtR optimal cutoffs were generally higher in non-Asian than in Asian populations. Moreover, medians of WHtR were also generally higher than the suggested cutoff of 0.500 in non-Asian individuals, and this was even the case in three out of four outcomes in Asian populations. Similar data are not presented for prospective studies because in four out of the ten included studies, cutoffs were not optimal but rather based on percentiles. A visual inspection of the cutoffs utilized in each data unit in prospective studies provides the impression that cutoffs are higher in non-Asians compared to Asians regarding incident DM and incident CVD.

\section{Results from cross-sectional studies with optimal cutoffs for BMI and WHtR}

Primary outcomes from these studies were DM, dyslipidemia, elevated blood pressure, and MetS. Results for DM are presented in Figure 2. The overall rRR clearly indicates that WHtR is superior to BMI in detecting DM (rRR: 0.71, 95\% CI: 0.59-0.84). The association of WHtR with DM was stronger for both Asians (rRR: 0.64, 95\% CI: 0.50-0.83) and non-Asians (rRR: 0.79, 95\% CI: 0.63-0.99). Moreover, subgroup analysis indicates that WHtR is also superior to BMI in discriminating DM in both male and female Asians and non-Asian females. 


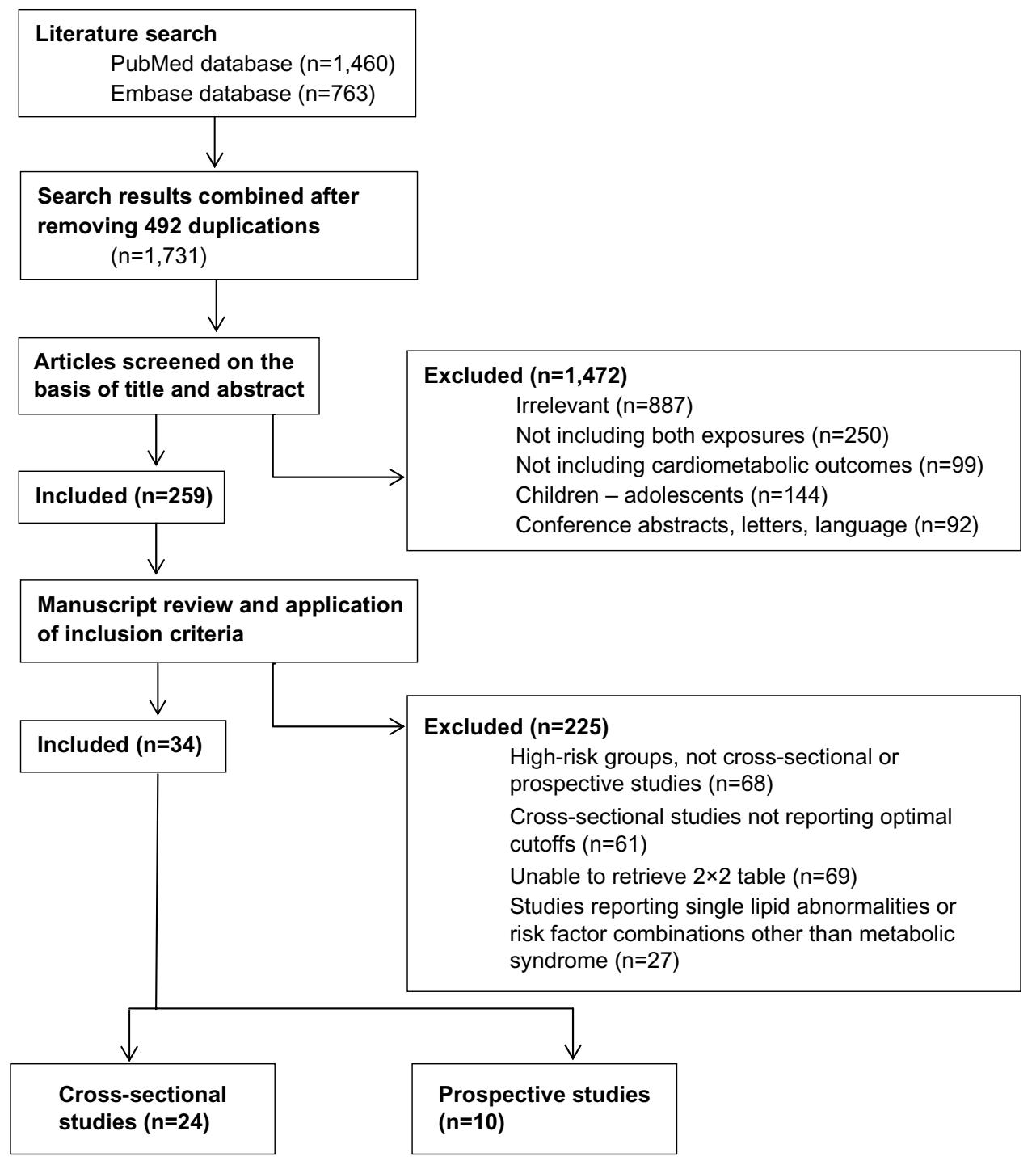

Figure I Flow diagram of study selection.

The overall comparison measure for dyslipidemia was in favor of neither of the exposures (rRR: 1.00, 95\% CI: 0.87-1.15), as shown in Figure 3. However, the comparison measure was statistically significant in favor of WHtR in Asian populations (rRR: 0.92, 95\% CI: 0.88-0.96), and this comparison remains statistically significant in favor of WHtR in both male and female Asians. In non-Asians, although the data units from the study of Berber et $\mathrm{al}^{21}$ were well in favor of BMI, neither exposure proved superior to the other (rRR:

\subsection{4, 95\% CI: 0.84-1.83).}

Similar findings were observed for elevated blood pressure, with the overall comparison measure (rRR: 0.95, 95\% CI: $0.83-1.11$ ) being in favor of neither of the two exposures (Figure 4), although it was in favor of WHtR in Asian populations (rRR: 0.87, 95\% CI: 0.77-0.98); however, the comparison measures attenuated within sex in Asians.
In non-Asians, the data units from the study of Berber et $\mathrm{al}^{21}$ again indicate a significantly stronger association of BMI with elevated blood pressure.

Finally, the overall comparison measure for MetS (Figure 5) was in favor of WHtR (rRR: 0.92, 95\% CI: 0.89-0.96). This was also true in Asian populations (rRR: 0.92, 95\% CI: 0.89-0.96) and in both male and female Asians. However, the two exposures performed equally in non-Asians (rRR: 0.92, 95\% CI: 0.81-1.03). The definition of MetS among utilized studies included WC in three out of the eight studies, ${ }^{35,38,41}$ two out of these three studies comprised non-Asians. Sensitivity analyses were used to explore the degree to which the findings were affected by these three studies. The overall rRR (ie, with ten data units after excluding the three studies) remained statistically significant in favor of WHtR (rRR: 0.93, 95\% CI: 0.89-0.97). 
Table I Characteristics of included studies

\begin{tabular}{|c|c|c|c|c|c|c|c|}
\hline Author & Ethnicity & $\begin{array}{l}\text { Ethnic } \\
\text { group }\end{array}$ & Sex & $\begin{array}{l}\text { Number of } \\
\text { participants }\end{array}$ & $\begin{array}{l}\text { Age range or } \\
\text { mean age } \pm \text { SD } \\
\text { (years) }\end{array}$ & $\begin{array}{l}\text { BMI and WHtR } \\
\text { cutoff selection }\end{array}$ & Outcome \\
\hline \multicolumn{8}{|c|}{ Cross-sectional studies with optimal cutoffs } \\
\hline $\mathrm{Al}-\mathrm{Odat}$ et $\mathrm{al}^{4 \mathrm{I}}$ & Jordanian & Non-Asian & $\mathrm{M}, \mathrm{F}$ & $212 ; 288$ & $20-85$ & Optimal & MetS \\
\hline Berber et $\mathrm{a}^{21}$ & Mexican & Non-Asian & $\mathrm{M}, \mathrm{F}$ & 2,$426 ; 5,939$ & $>20$ & Optimal & DM, Dys, EBP \\
\hline Craig et $\mathrm{a}^{22}$ & Tongan & Non-Asian & $\mathrm{M}, \mathrm{F}$ & $314 ; 453$ & $>15$ & Optimal & DM, EBP \\
\hline Deshmukh et a ${ }^{36}$ & Indian & Asian & $\mathrm{M}, \mathrm{F}$ & I,059; I,64I & $>18$ & Optimal & EBP \\
\hline Dong et $\mathrm{a}^{23}$ & Chinese & Asian & $\mathrm{M}, \mathrm{F}$ & I,522; I,484 & $20-74$ & Optimal & DM, Dys, EBP, MetS \\
\hline He et $\mathrm{al}^{42}$ & Chinese & Asian & $\mathrm{M}, \mathrm{F}$ & $430 ; 638$ & $>40$ & Optimal & MetS \\
\hline Ho et $\mathrm{al}^{24}$ & $\begin{array}{l}\text { Hong Kong } \\
\text { Chinese }\end{array}$ & Asian & $\mathrm{M}, \mathrm{F}$ & $\mathrm{I}, 4 \mid 2 ; \mathrm{I}, 483$ & $27-74$ & Optimal & DM, Dys, EBP \\
\hline Hsu et $\mathrm{al}^{35}$ & Taiwanese & Asian & $\mathrm{M}, \mathrm{F}$ & I,I47; I,2I2 & $40-94$ & Optimal & Dys, EBP, MetS \\
\hline Khader et $\mathrm{al}^{37}$ & Jordanian & Non-Asian & $\mathrm{M}, \mathrm{F}$ & $\mathrm{I}, 128 ; 3,462$ & $>18$ & Optimal & EBP \\
\hline Ko et $\mathrm{a}^{25}$ & $\begin{array}{l}\text { Hong Kong } \\
\text { Chinese }\end{array}$ & Asian & $\mathrm{M}, \mathrm{F}$ & $910 ; 603$ & $36.6 \pm 9.2$ & Optimal & DM, Dys, EBP \\
\hline Li et $\mathrm{a}^{26}$ & US & Non-Asian & $\mathrm{M}, \mathrm{F}$ & 2,$994 ; 3,283$ & $>20$ & Optimal & DM \\
\hline $\mathrm{Li}$ and $\mathrm{McDermott}{ }^{27}$ & $\begin{array}{l}\text { Australian } \\
\text { Aboriginal }\end{array}$ & Non-Asian & $\mathrm{M}, \mathrm{F}$ & $760 ; 881$ & $15-74$ & Optimal & DM, Dys, EBP \\
\hline Li et $\mathrm{a}^{28}$ & Taiwanese & Asian & $\mathrm{M}, \mathrm{F}$ & 21,$038 ; 15,604$ & $37.2 \pm 9.4$ & Optimal & DM, EBP \\
\hline Lin et $\mathrm{al}^{29}$ & Chinese & Asian & $\mathrm{M}, \mathrm{F}$ & 26,$359 ; 29,204$ & $37.3 \pm 10.9$ & Optimal & DM, Dys, EBP \\
\hline $\begin{array}{l}\text { Mansour and } \\
\text { Al-Jazairi }^{30}\end{array}$ & Iraqi & Non-Asian & $\mathrm{M}, \mathrm{F}$ & 6,$693 ; 6,293$ & $>18$ & Optimal & DM, EBP \\
\hline Nakamura et al ${ }^{43}$ & Japanese & Asian & $\mathrm{M}, \mathrm{F}$ & $330 ; 514$ & $40-69$ & Optimal & MetS \\
\hline Park et $\mathrm{al}^{31}$ & Korean & Asian & $\mathrm{M}, \mathrm{F}$ & 2,$327 ; 3,102$ & $>20$ & Optimal & DM, EBP \\
\hline Pua and Ong ${ }^{32}$ & Singaporean & Asian & $\mathrm{F}$ & 566 & $18-68$ & Optimal & DM, Dys, EBP \\
\hline Rodrigues et $\mathrm{a}^{38}$ & Brazilian & Non-Asian & $\mathrm{M}, \mathrm{F}$ & $759 ; 896$ & $25-64$ & Optimal & EBP, MetS \\
\hline Schneider et al ${ }^{33}$ & German & Non-Asian & $M, F$ & 2,$016 ; 3,361$ & $20-79$ & Optimal & DM, Dys, MetS \\
\hline Silva et $\mathrm{a}^{39}$ & Brazilian & Non-Asian & $M, F$ & $754 ; 928$ & $20-59$ & Optimal & EBP \\
\hline Singh et $\mathrm{al}^{40}$ & Indian & Asian & $\mathrm{M}, \mathrm{F}$ & 3,118 & $>30$ & Optimal & EBP \\
\hline Tseng et $\mathrm{al}^{34}$ & Taiwanese & Asian & $\mathrm{M}, \mathrm{F}$ & 2,$280 ; 2,403$ & $44.5 \pm 11.9$ & Optimal & DM, Dys, EBP \\
\hline $\begin{array}{l}\text { Wakabayashi and } \\
\text { Daimon }{ }^{44}\end{array}$ & Japanese & Asian & $\mathrm{M}, \mathrm{F}$ & 37,$697 ; \mid 9,891$ & $35-70$ & Optimal & MetS \\
\hline \multicolumn{8}{|l|}{ Prospective studies } \\
\hline Aekplakorn et al ${ }^{50}$ & Thai & Asian & M & 2,536 & $35-59$ & Optimal & Incident CVD \\
\hline Chei et al ${ }^{45}$ & Japanese & Asian & $\mathrm{M}, \mathrm{F}$ & $974 ; 1,998$ & $40-69$ & Percentiles & Incident DM \\
\hline Gelber et $\mathrm{al}^{51}$ & US & Non-Asian & $\mathrm{M}, \mathrm{F}$ & 16,$332 ; 32,700$ & $40-84 ; \geq 45$ & Percentiles & Incident CVD \\
\hline Huerta et $\mathrm{al}^{46}$ & Spanish & Non-Asian & $M, F$ & $|4,0| 9 ; 23,7 \mid 4$ & $30-65$ & Optimal & Incident DM \\
\hline Jia et $\mathrm{a}^{47}$ & Chinese & Asian & $M, F$ & 48,$015 ; 13,688$ & $18-85$ & Optimal & Incident DM \\
\hline Petursson et al ${ }^{53}$ & Norwegian & Non-Asian & $\mathrm{M}, \mathrm{F}$ & $26,46 I ; 30,510$ & $20-79$ & Percentiles & $\begin{array}{l}\text { All-cause mortality, } \\
\text { CVD mortality }\end{array}$ \\
\hline Sargeant et $\mathrm{al}^{48}$ & Jamaican & Non-Asian & $M, F$ & $290 ; 438$ & $25-74$ & Optimal & Incident DM \\
\hline Welborn and Dhaliwal ${ }^{54}$ & Australian & Non-Asian & $\mathrm{M}, \mathrm{F}$ & 4,$508 ; 4,698$ & $20-69$ & Optimal & $\begin{array}{l}\text { All-cause mortality, } \\
\text { CVD mortality }\end{array}$ \\
\hline Xu et a $\left.\right|^{49}$ & Chinese & Asian & $\mathrm{M}, \mathrm{F}$ & I,384; I,647 & $>35$ & Optimal & Incident DM \\
\hline Zhang et a ${ }^{52}$ & Chinese & Asian & $\mathrm{F}$ & 67,083 & $40-70$ & Percentiles & Incident CVD \\
\hline
\end{tabular}

Abbreviations: BMI, body mass index; CVD, cardiovascular disease; DM, diabetes mellitus; Dys, dyslipidemia; EBP, elevated blood pressure; MetS, metabolic syndrome; $\mathrm{SD}$, standard deviation; $\mathrm{WH} t \mathrm{R}$, waist-to-height ratio.

Similarly, in Asians, after removing the study of Hsu et al ${ }^{35}$ (ie, eight data units), the association remained statistically significant in favor of WHtR (rRR: $0.93,95 \%$ CI: $0.89-0.97$ ). A similar analysis was not performed in non-Asians because of the limited number of studies.

\section{Results from prospective studies}

Associations from available prospective studies are presented in Figure 6. The assessed outcomes were incident DM, incident CVD, CVD mortality, and all-cause mortality. Regarding the two mortality outcomes, data were available only from 
Table 2 Summary of optimal exposure cutoffs from cross-sectional studies

\begin{tabular}{|c|c|c|c|c|}
\hline \multirow[t]{2}{*}{ Outcome } & \multicolumn{2}{|l|}{ Asians } & \multicolumn{2}{|l|}{ Non-Asians } \\
\hline & Number of data units & Median (min, max) & Number of data units & Median (min, max) \\
\hline \multicolumn{5}{|l|}{ Waist-to-height ratio } \\
\hline Diabetes mellitus & 15 & $0.510(0.480,0.530)$ & 12 & $0.560(0.500,0.620)$ \\
\hline Dyslipidemia & 13 & $0.480(0.450,0.520)$ & 6 & $0.526(0.500,0.600)$ \\
\hline Elevated blood pressure & 20 & $0.510(0.450,0.530)$ & 14 & $0.528(0.490,0.600)$ \\
\hline Metabolic syndrome & 10 & $0.520(0.500,0.540)$ & 6 & $0.550(0.530,0.610)$ \\
\hline \multicolumn{5}{|l|}{ Body mass index $\left(\mathrm{kg} / \mathrm{m}^{2}\right)$} \\
\hline Diabetes mellitus & 15 & $24.3(23.2,25.5)$ & 12 & $26.1(23.8,35.0)$ \\
\hline Dyslipidemia & 13 & $23.7(22.1,25.0)$ & 6 & $25.2(23.9,26.8)$ \\
\hline Elevated blood pressure & 20 & $24.1(21.2,26.3)$ & 14 & $26.2(23.6,31.7)$ \\
\hline Metabolic syndrome & 10 & $24.3(22.6,26.0)$ & 6 & $26.7(25.8,30.3)$ \\
\hline
\end{tabular}

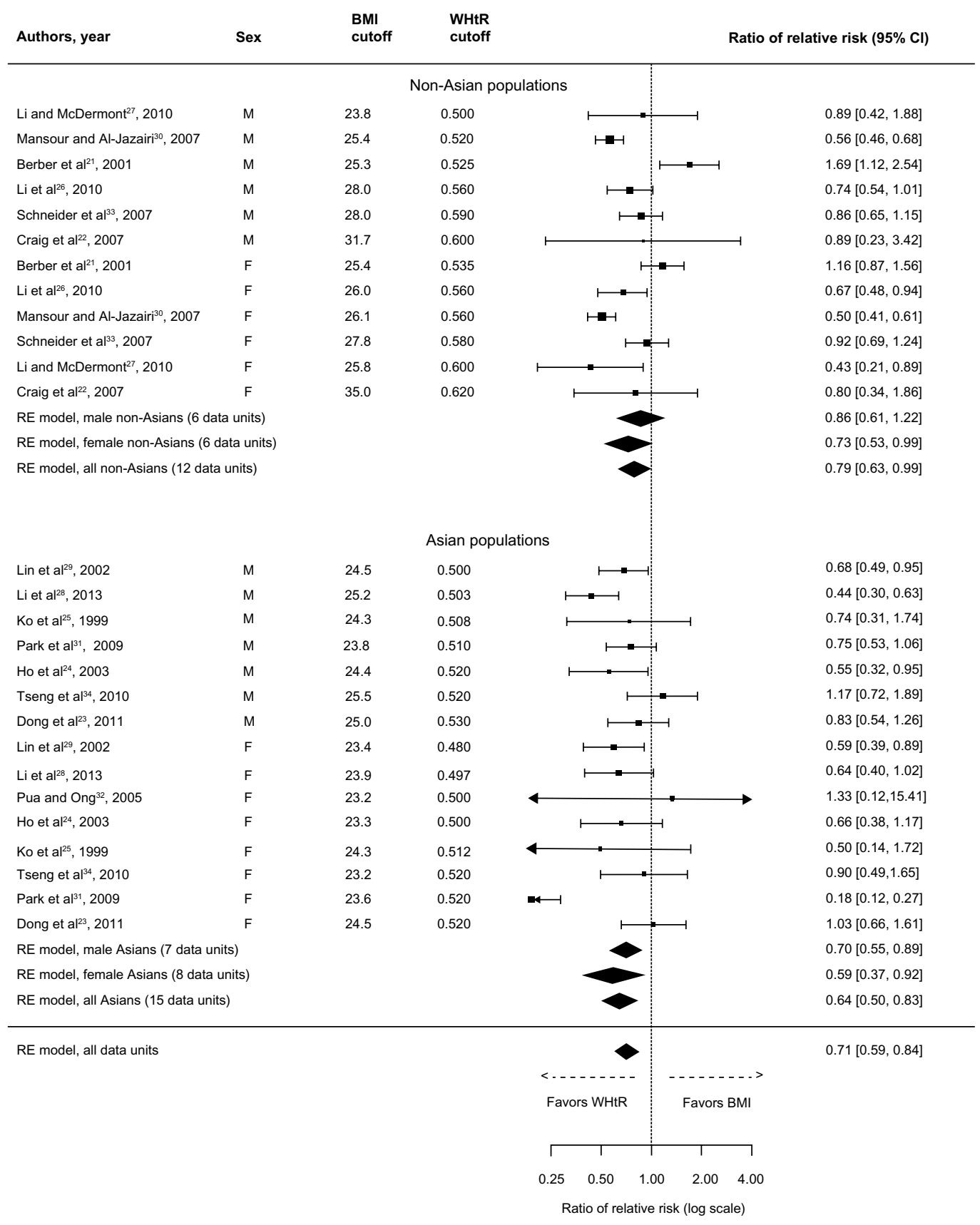

Figure 2 Forest plot for discrimination of diabetes mellitus in cross-sectional studies with optimal BMI and WHtR cutoffs.

Abbreviations: $\mathrm{BMI}$, body mass index; $\mathrm{Cl}$, confidence interval; $\mathrm{RE}$, random effects; $\mathrm{WH} \mathrm{tR}$, waist-to-height ratio. 


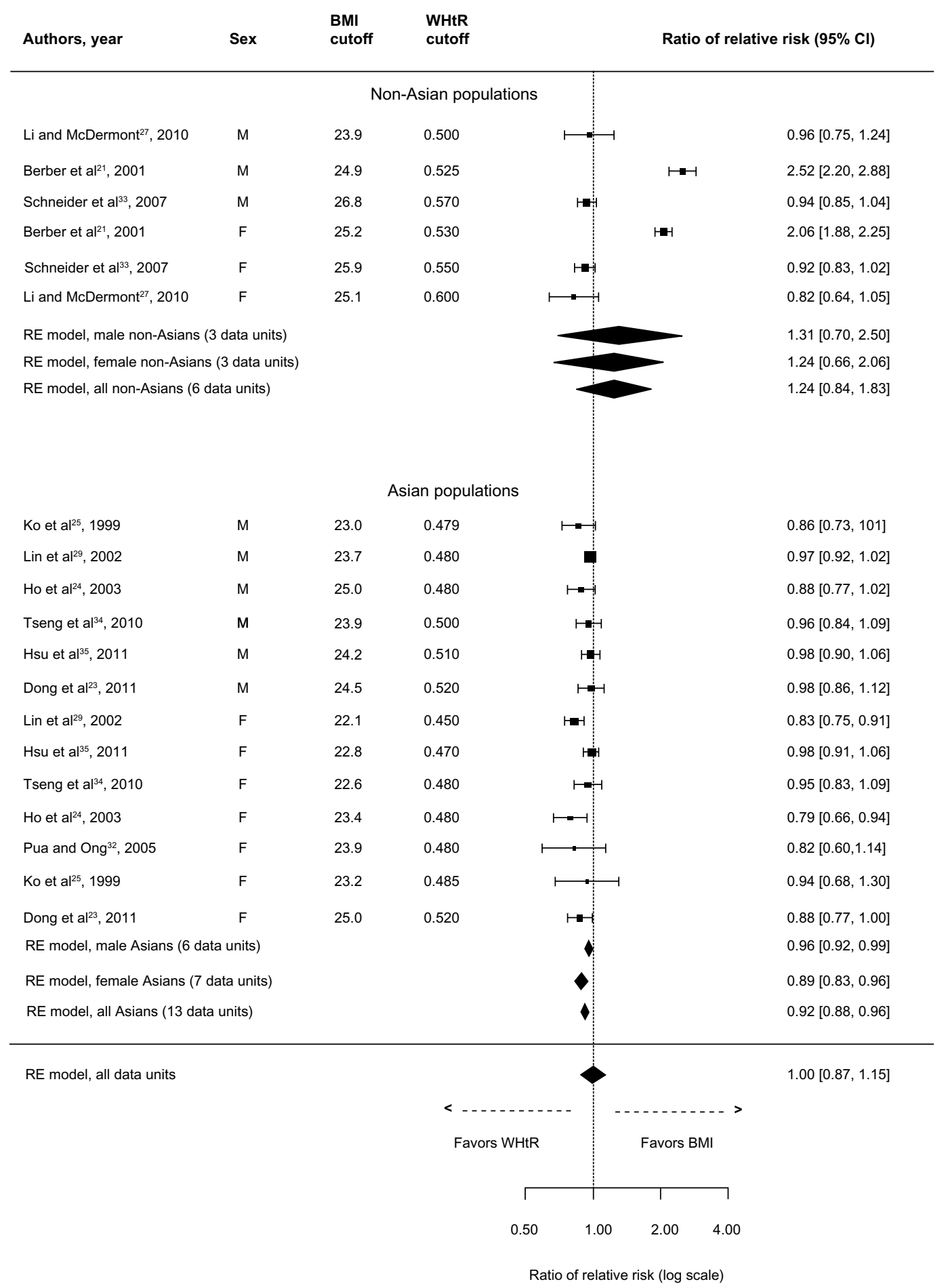

Figure 3 Forest plot for discrimination of dyslipidemia in cross-sectional studies with optimal BMI and WHtR cutoffs. Abbreviations: $\mathrm{BMI}$, body mass index; $\mathrm{Cl}$, confidence interval; $\mathrm{RE}$, random effects; $\mathrm{WHtR}$, waist-to-height ratio.

non-Asian populations. Although there were only four data units from only two studies for each mortality outcome, the results were well in favor of WHtR compared to BMI; pooled rRR for CVD mortality was 0.42 ( $95 \%$ CI: $0.35-0.50$ ) and, for all-cause mortality, 0.49 (95\% CI: 0.41-0.59). Results were also in favor of WHtR compared to BMI regarding incident
CVD in both Asians (rRR: $0.64,95 \%$ CI: $0.57-0.72$ ) and nonAsians (rRR: 0.75, 95\% CI: 0.64-0.87). Finally, WHtR was superior in detecting incident DM in Asian populations (rRR: 0.90, 95\% CI: $0.81-0.99)$ but not in non-Asian populations (rRR: 0.91, 95\% CI: 0.78-1.05). Due to the small number of data units, within-sex analyses were not performed. 


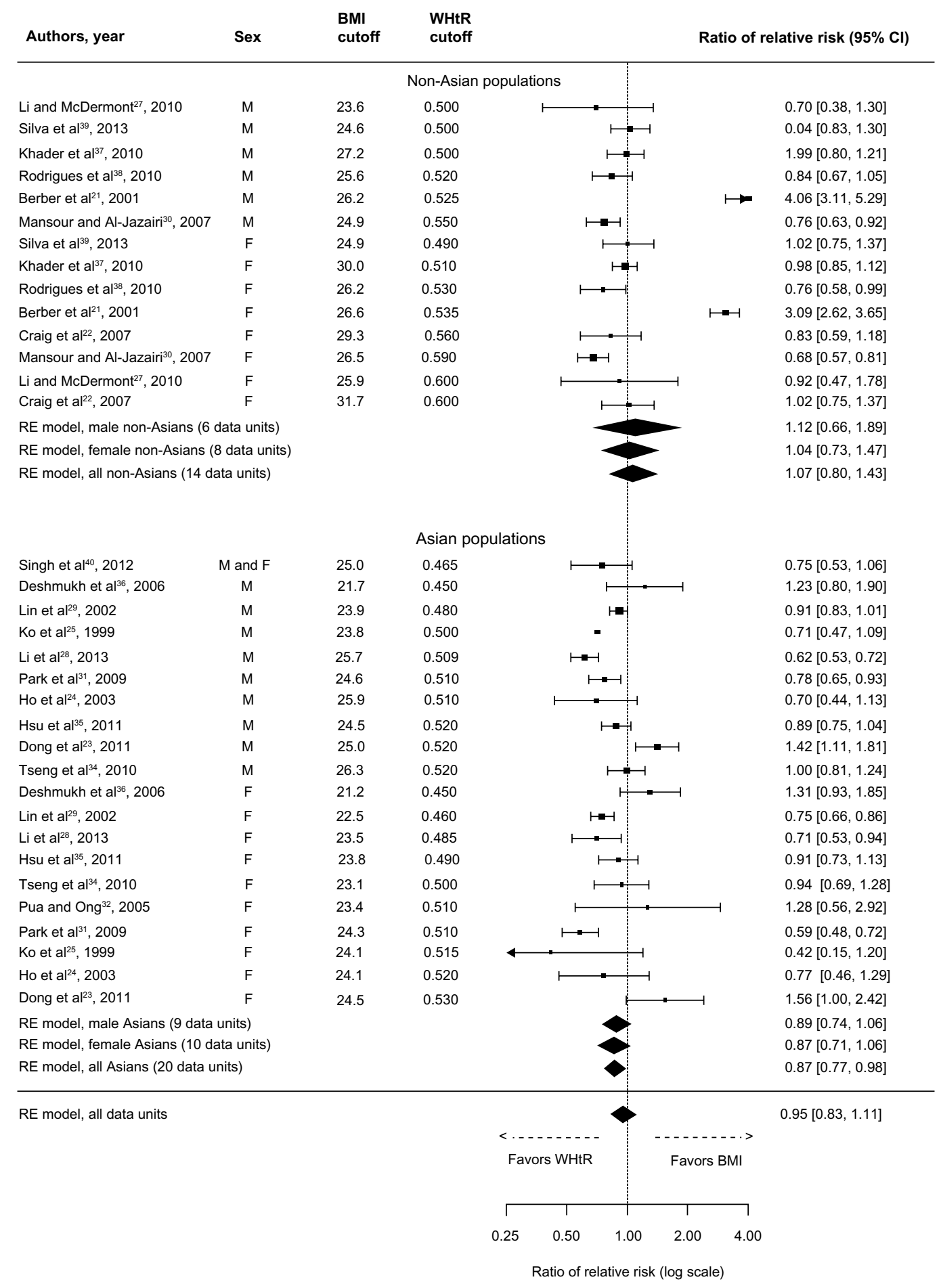

Figure 4 Forest plot for discrimination of elevated blood pressure in cross-sectional studies with optimal BMI and WHtR cutoffs. Abbreviations: $\mathrm{BMI}$, body mass index; $\mathrm{Cl}$, confidence interval; $\mathrm{RE}$, random effects; $\mathrm{WH} \mathrm{R}$, waist-to-height ratio.

\section{Quality assessment}

Results of quality assessment for the selected studies are presented in Tables S1 and S2. In prospective studies (Table S1), eight out of the ten studies received 7 or 8 stars; two studies received lower scores, ie, the study of Jia et al ${ }^{47}$ in Asians and the study of Sargeant et $\mathrm{l}^{48}$ in non-Asians, both of which gave data for incident DM. Sensitivity analysis in Asians, excluding the study of Jia et al, ${ }^{47}$ attenuated the association (rRR: $0.84,95 \%$ CI: $0.55-1.27$ ). Sensitivity analysis in non-Asians did not alter the association, which remained in favor of neither of the exposures (rRR: 0.90, 95\% CI: 0.73-1.12). 


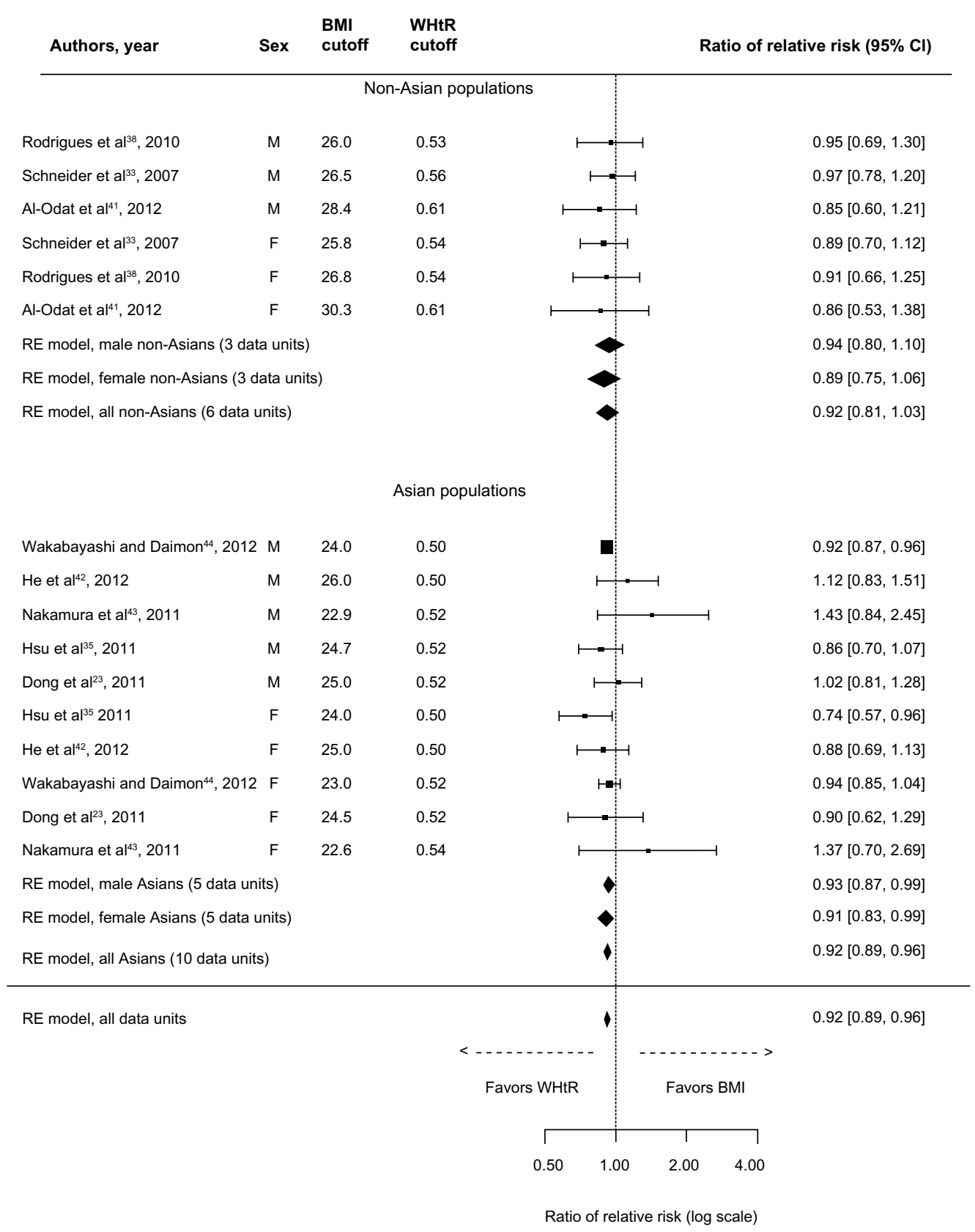

Figure 5 Forest plot for discrimination of metabolic syndrome in cross-sectional studies with optimal BMI and WHtR cutoffs. Abbreviations: $\mathrm{BMI}$, body mass index; $\mathrm{Cl}$, confidence interval; RE, random effects; WHtR, waist-to-height ratio.

In cross-sectional studies, 22 of the included 24 studies received 4 or 5 stars out of the maximum 5 . Two studies scored 3 stars - the study of Berber et $\mathrm{al}^{21}$ in non-Asians and the study of Tseng et $\mathrm{al}^{34}$ in Asians. Both studies gave data for the outcomes of DM, elevated blood pressure, and dyslipidemia. Sensitivity analysis, excluding results from the study of Tseng et al in Asians, ${ }^{34}$ did not alter the findings. In non-Asians, excluding the study of Berber et $\mathrm{al}^{21}$ did not alter the association for DM, which remained in favor of WHtR; however, it resulted in statistically significant associations in favor of WHtR regarding elevated blood pressure
(rRR: 0.87, 95\% CI: 0.79-0.96) and dyslipidemia (rRR: 0.92, 95\% CI: 0.86-0.99).

\section{Heterogeneity and publication biases}

A substantial heterogeneity among the results was observed in those outcomes having low uncertainty in $\mathrm{I}^{2}$ (Table 3 ). The low uncertainty in $\mathrm{I}^{2}$ is indicated by the relatively small range of its $95 \% \mathrm{CI}$. This substantial heterogeneity is not surprising, given the observed differences between Asians and non-Asians. When there was a high uncertainty in $\mathrm{I}^{2}$, then no safe conclusions could be made about the 


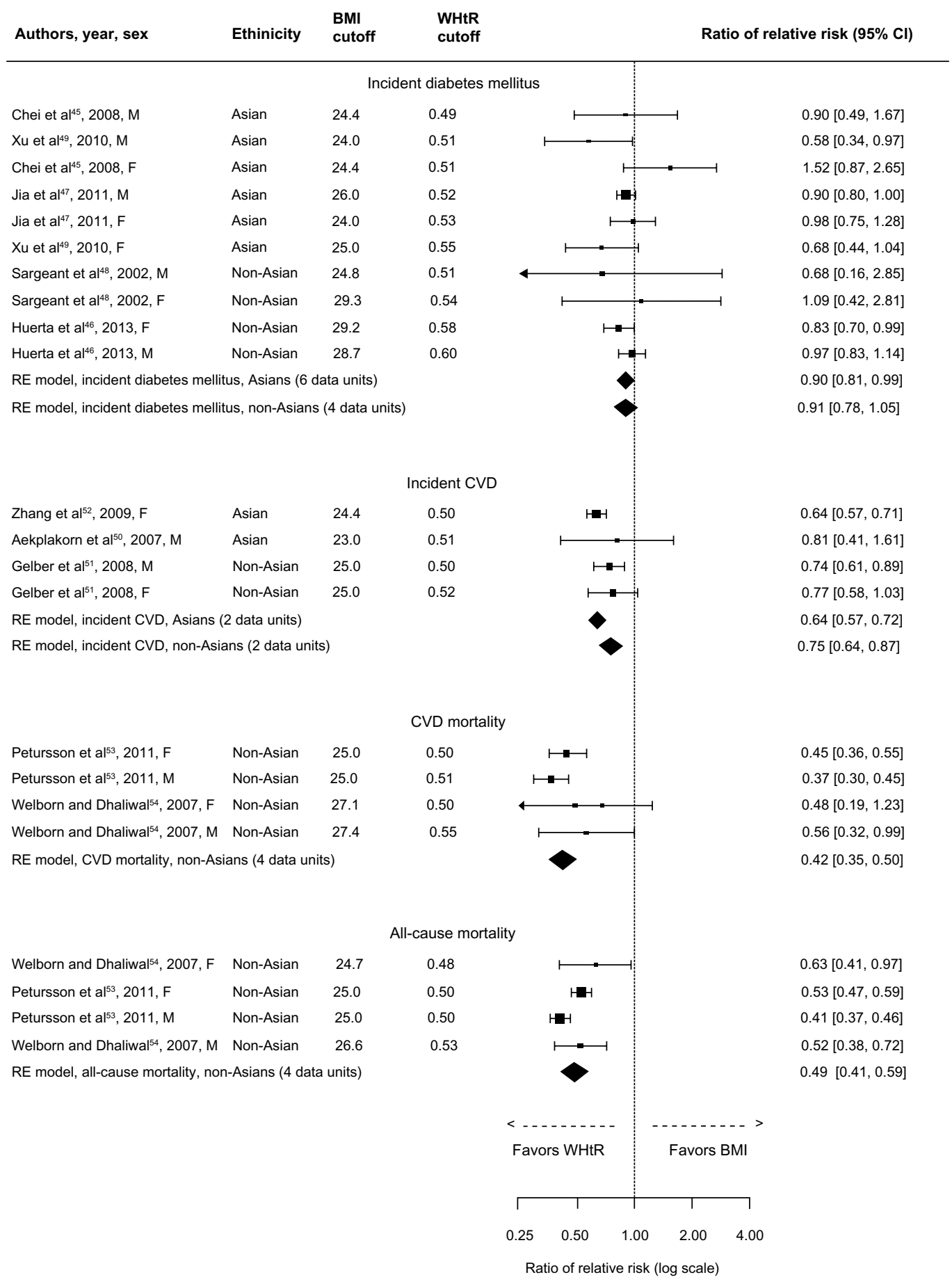

Figure 6 Forest plot for discrimination of incident diabetes mellitus, incident CVD, CVD mortality, and all-cause mortality in prospective studies with BMl and WHtR. Abbreviations: $\mathrm{BMI}$, body mass index; $\mathrm{Cl}$, confidence interval; $\mathrm{CVD}$, cardiovascular disease; $\mathrm{RE}$, random effects; $\mathrm{WH} \mathrm{R}$, waist-to-height ratio.

heterogeneity of the results. We further explored betweenstudy heterogeneity by meta-regression analysis for the predefined study-level covariates in outcomes from the cross-sectional studies (Table S3). None of these covariates has a significant relationship with the $\log$ of RR and, therefore, they cannot help in explaining the heterogeneity between the studies.
Regarding publication bias, Egger's regression tests imply that there is asymmetry in the funnel plots regarding DM in cross-sectional studies for both BMI and WHtR, both overall and in Asians. There was also an indication for asymmetry in the funnel plot regarding CVD mortality in BMI studies. In the remaining outcomes, there was no indication of possible publication bias. 
Table 3 Study heterogeneity and publication biases

\begin{tabular}{|c|c|c|c|c|c|}
\hline \multirow[t]{2}{*}{ Outcome, origin } & \multirow[t]{2}{*}{ Study type } & \multirow[t]{2}{*}{$\begin{array}{l}\text { Number of } \\
\text { data units }\end{array}$} & \multirow[t]{2}{*}{$\begin{array}{l}I^{2} \\
(95 \% \mathrm{CI})\end{array}$} & \multicolumn{2}{|c|}{$\begin{array}{l}\text { Asymmetry test* } \\
\text { (z statistic) }\end{array}$} \\
\hline & & & & BMI & WHtR \\
\hline Diabetes mellitus & Cross-sectional & & & & \\
\hline All & & 27 & $78.8(60.7,87.6)$ & $2.439 *$ & $2.163^{*}$ \\
\hline Asians & & 15 & $74.4(47.7,88.2)$ & $2.078^{*}$ & $1.865^{*}$ \\
\hline Non-Asians & & 12 & $79.3(52.4,92.5)$ & 0.980 & 0.809 \\
\hline Dyslipidemia & Cross-sectional & & & & \\
\hline All & & 19 & $96.2(93.2,98.3)$ & 0.383 & 1.247 \\
\hline Asians & & 13 & $39.5(0,75.7)$ & 0.206 & 0.527 \\
\hline Non-Asians & & 6 & $98.2(95.3,99.7)$ & 0.384 & 1.549 \\
\hline Elevated blood pressure & Cross-sectional & & & & \\
\hline All & & 34 & $92.5(87.7,95.6)$ & 1.150 & $1.65 \mathrm{I}$ \\
\hline Asians & & 20 & $80.0(61.7,92.4)$ & 1.694 & 1.680 \\
\hline Non-Asians & & 14 & $95.3(90.7,98.1)$ & -1.466 & -0.316 \\
\hline Metabolic syndrome & Cross-sectional & & & & \\
\hline All & & 16 & $0(0,67.3)$ & 1.089 & 0.069 \\
\hline Asians & & 10 & $0.02(0,92.4)$ & 1.236 & 0.102 \\
\hline Non-Asians & & 6 & $0(\mathrm{NA})$ & -0.037 & -0.044 \\
\hline Incident diabetes mellitus & Prospective & & & & \\
\hline Asians & & 6 & $0.1(0,95.7)$ & -1.322 & -1.353 \\
\hline Non-Asians & & 4 & $18.2(1.0,92.8)$ & 0.214 & 0.378 \\
\hline Incident CVD & Prospective & & & & \\
\hline Asians & & 2 & $0(0,99.8)$ & NA & NA \\
\hline Non-Asians & & 2 & $0(0,98.3)$ & NA & NA \\
\hline CVD mortality & Prospective & & & & \\
\hline Non-Asians & & 4 & $17.8(0,93.1)$ & $2.173^{*}$ & 1.229 \\
\hline All-cause mortality & Prospective & & & & \\
\hline Non-Asians & & 4 & $71.3(12.1,98.1)$ & 1.285 & 0.525 \\
\hline
\end{tabular}

Note: ${ }^{*} P$-value for $z$ statistic $<0.05$.

Abbreviations: BMI, body mass index; $\mathrm{Cl}$, confidence interval; $\mathrm{CVD}$, cardiovascular disease; NA, not applicable; WHtR, waist-to-height ratio.

\section{Discussion}

\section{Summary of evidence}

This meta-analysis was based on 34 studies, of which 24 were cross-sectional and ten prospective, with more than 500,000 participants. The results demonstrate that the pooled rRR of BMI to WHtR was in favor of WHtR in detecting DM, dyslipidemia, elevated blood pressure, and MetS in Asian populations and DM in non-Asian populations in crosssectional studies. At this point, it should be noted that, in non-Asian populations, as far as dyslipidemia and elevated blood pressure are concerned, data from the study of Berber et $\mathrm{al}^{21}$ appear to be extremely in favor of BMI. However, the quality assessment of this study was rather poor, and when we removed these data units from the analysis, the pooled rRR proved also in favor of WHtR in both outcomes. WHtR was also superior to BMI in detecting incident DM and incident CVD in Asian populations and incident CVD, CVD mortality, and all-cause mortality in non-Asian populations in prospective studies. Regarding CVD mortality and all-cause mortality outcomes, it should be noted that data were available only from non-Asian populations. The performance of
rRR was generally similar in male and female participants in cross-sectional studies, whereas sex-specific analysis was not performed in prospective studies because of the limited number of data units. BMI did not prove superior to WHtR in any of the evaluated outcomes when all data units were analyzed, or within ethnicity and sex subgroup analysis.

\section{Considerations about this meta-analysis}

To the best of our knowledge, this is the first meta-analysis that has examined the pooled rRR of BMI to WHtR in detecting cardiometabolic outcomes using optimal cutoffs of the two exposure measures. The superiority of WHtR compared to BMI in certain cardiometabolic outcomes documented in our meta-analysis is in line with other meta-analyses that demonstrated that WHtR is superior to BMI in detecting several cardiometabolic risk factors ${ }^{12}$ and, particularly, DM. ${ }^{14}$ On the other hand, two other meta-analyses did not provide evidence that WHtR was superior to BMI or that BMI was superior to WHtR in detecting cardiometabolic risk. ${ }^{13,15}$

Obesity remains a huge challenge globally, because it is one of the most important causes of premature death. 
In an effort to optimize identification of high-risk individuals, new indices are proposed, such as the Body Shape Index. ${ }^{55}$ There are, however, several reasons why WHtR has been proposed as a useful single global index to determine health risks. ${ }^{10}$ The results from the present and other meta-analyses, when taken together, may justify the use of WHtR or other abdominal obesity proxy measures as a single screening tool for cardiometabolic risk rather than BMI. This may be justified given the low sensitivity of BMI in detecting excess body fat ${ }^{56}$ and metabolic risk ${ }^{57}$ and because of the "J"-shape association of BMI with cardiovascular risk stratification. ${ }^{56}$ Compared to WC, which is currently the most widely used index of abdominal obesity, WHtR is thought to be better in discriminating cardiometabolic risk because it takes into account height, which is important particularly in shorter individuals. ${ }^{58}$

One of the proposed advantages in using WHtR instead of BMI is the ability to use one single cutoff point (0.5) in all ages, both sexes, and all ethnicities. ${ }^{11,57,59}$ This provides a simple public health message: "Keep your waist circumference to less than half your height." ${ }^{11}$ However, it should be noted that our results from cross-sectional studies indicated that the optimal cutoff of WHtR was substantially higher than the simple cutoff of 0.5 , particularly in non-Asians. Therefore, we may argue that the use of this single cutoff point is not justified with the results of the present meta-analysis and that further evidence is warranted to clarify this issue.

One of the issues pertaining to WHtR is the point of WC measurement. It has been suggested that measuring $\mathrm{WC}$ at the level of umbilicus rather than at the narrowest point between the lower costal border and the top of the iliac crest improves sensitivity in detecting percent excess fat, particularly in women. ${ }^{60}$ On the other hand, Ashwell and Browning have suggested measuring WC midway between the lower rib and iliac crest simply because this was the most often-used measurement they found in a review and because this was the preferred site of measurement recommended by the World Health Organization (WHO). ${ }^{61}$

\section{Limitations}

The main advantage of a meta-analysis is the calculation of effect sizes with more precision compared to data of a single study. Although we aimed to choose specific and robust cutoffs for the definition of the utilized outcomes for this meta-analysis, outcome-specific bias cannot be excluded due to the combination of data from different studies in which different definitions for each outcome were used. Furthermore, as far as certain outcomes are concerned, the number of available studies was limited. There were only three studies for dyslipidemia and MetS in non-Asians, three studies for incident CVD, and just two studies for CVD and all-cause mortality.

The small number of included studies for certain outcomes in non-Asians prevented us from further evaluating the discriminating ability of BMI and WHtR within non-Asian subpopulations, such as Caucasians, blacks, and so on. This would be an important task given the current WHO recommendation of using a single BMI cutoff for non-Asians, but also on the suggestion of using a single cutoff of WHtR in evaluating cardiometabolic risk. ${ }^{11}$

In this meta-analysis, participants belonging to any ethnicity were included. Therefore, we opted to use studies reporting results based on optimal cutoffs for the exposure indices rather than the "standard" cutoffs (eg, WHtR 0.5, BMI $23 \mathrm{~kg} / \mathrm{m}^{2}$ in Asians or $25 \mathrm{~kg} / \mathrm{m}^{2}$ in non-Asians). However, in prospective studies, we included studies irrespective of selection of exposure cutoffs because of the limited number of data units in certain outcomes. Another issue with prospective studies is the unknown effect of follow-up duration (ranges from 2 to 17 years) on the estimated effect size.

In the present meta-analysis, we opted to compare the discriminative analysis of BMI, which is an index of general adiposity, with WHtR, an index of abdominal adiposity, in detecting cardiometabolic risk for those reasons already mentioned. However, it should be underlined that other indices measuring abdominal adiposity have been also found to be superior to BMI. Although Ashwell et al ${ }^{12}$ have demonstrated that WHtR is superior to WC in detecting cardiometabolic risk, more research may be needed to document this superiority.

Publication bias might account for some of the observed effect sizes regarding DM in cross-sectional studies and CVD mortality. Moreover, the results of this meta-analysis should be interpreted cautiously because of the presence of heterogeneity in some of the outcomes and the high uncertainty about $\mathrm{I}^{2}$ statistics in other outcomes. Meta-regression showed that none of the predefined covariates could explain part of the heterogeneity between the studies in the outcomes regarding DM, elevated blood pressure, dyslipidemia, and MetS in cross-sectional studies.

\section{Conclusion}

This meta-analysis provides evidence that WHtR is superior to BMI in detecting several cardiometabolic risk factors, both in cross-sectional and prospective studies. Despite the heterogeneity of results among studies and evidence of asymmetry in 
some of the outcomes, it is important to emphasize that BMI was not superior to WHtR in detecting any of the evaluated outcomes in this study, and thus we conclude that WHtR can be used as a screening tool for cardiometabolic risk at least as efficiently as BMI in both Asian and non-Asian populations.

\section{Acknowledgment}

The authors are grateful to George Kafatos for his critical comments on the manuscript draft. They are also grateful to Nanette Christou for her valuable help in the preparation of the manuscript.

\section{Disclosure}

The evidence synthesis upon which this meta-analysis was based was not funded by any external source. The authors report no conflicts of interest in this work.

\section{References}

1. Duggleby SL, Jackson AA, Godfrey KM, Robinson SM, Inskip HM; Southampton Women's Survey Study Group. Cut-off points for anthropometric indices of adiposity: differential classification in a large population of young women. Br J Nutr. 2009;101(3):424-430.

2. Vazquez G, Duval S, Jacobs DR Jr, Silventoinen K. Comparison of body mass index, waist circumference, and waist/hip ratio in predicting incident diabetes: a meta-analysis. Epidemiol Rev. 2007;29(1):115-128.

3. de Koning L, Merchant AT, Pogue J, Anand SS. Waist circumference and waist-to-hip ratio as predictors of cardiovascular events: meta-regression analysis of prospective studies. Eur Heart J. 2007; 28(7):850-856.

4. Czernichow S, Kengne AP, Stamatakis E, Hamer M, Batty GD. Body mass index, waist circumference and waist-hip ratio: which is the better discriminator of cardiovascular disease mortality risk?: evidence from an individual-participant meta-analysis of 82864 participants from nine cohort studies. Obes Rev. 2011;12(9):680-687.

5. Ashwell M, Cole TJ, Dixon AK. Ratio of waist circumference to height is strong predictor of intra-abdominal fat. $\mathrm{Br}$ Med J. 1996; 313(7056):559-560.

6. Cox BD, Whichelow M. Ratio of waist circumference to height is better predictor of death than body mass index. Br Med J. 1996; 313(7070): 1487.

7. Hsieh SD, Yoshinaga H. Waist/height ratio as a simple and useful predictor of coronary heart disease risk factors in women. Intern Med. 1995;34(12):1147-1152.

8. Savva SC, Tornaritis M, Savva ME, et al. Waist circumference and waist-to-height ratio are better predictors of cardiovascular disease risk factors in children than body mass index. Int $J$ Obes Relat Metab Disord. 2000;24(11):1453-1458.

9. Hara M, Saitou E, Iwata F, Okada T, Harada K. Waist-to-height ratio is the best predictor of cardiovascular disease risk factors in Japanese schoolchildren. J Atheroscler Thromb. 2002;9(3):127-132.

10. Ashwell M, Hsieh SD. Six reasons why the waist-to-height ratio is a rapid and effective global indicator for health risks of obesity and how its use could simplify the international public health message on obesity. Int J Food Sci Nutr. 2005;56(5):303-307.

11. Browning LM, Hsieh SD, Ashwell M. A systematic review of waistto-height ratio as a screening tool for the prediction of cardiovascular disease and diabetes: 0.5 could be a suitable global boundary value. Nutr Res Rev. 2010;23(2):247-269.
12. Ashwell M, Gunn P, Gibson S. Waist-to-height ratio is a better screening tool than waist circumference and BMI for adult cardiometabolic risk factors: systematic review and meta-analysis. Obes Rev. 2012;13(3):275-286.

13. Barzi F, Woodward M, Czernichow S, et al. The discrimination of dyslipidaemia using anthropometric measures in ethnically diverse populations of the Asia-Pacific Region: the Obesity in Asia Collaboration. Obes Rev. 2010;11(2):127-136.

14. Kodama S, Horikawa C, Fujihara $\mathrm{K}$, et al. Comparisons of the strength of associations with future type 2 diabetes risk among anthropometric obesity indicators, including waist-to-height ratio: a meta-analysis. Am J Epidemiol. 2012;176(11):959-969.

15. van Dijk S, Takken T, Prinsen E, Wittink H. Different anthropometric adiposity measures and their association with cardiovascular disease risk factors: a meta-analysis. Neth Heart J. 2012;20(5):208-218.

16. Friedemann C, Heneghan C, Mahtani K, Thompson M, Perera R, Ward AM. Cardiovascular disease risk in healthy children and its association with body mass index: systematic review and meta-analysis. Br Med J. 2012;345:e4759.

17. Wells G, Shea B, O'Connel D, et al. The Newcastle-Ottawa Scale (NOS) for assessing the quality of nonrandomised studies in meta-analyses [webpage on the Internet]. Ottawa, ON: Ottawa Hospital Research Institute; 2013. Available from: http://www.ohri.ca/programs/clinical_ epidemiology/oxford.asp. Accessed August 2, 2013.

18. DerSimonian R, Laird N. Meta-Analysis in Clinical Trials. Control Clinl Trials. 1986; 7(3), 177-188.

19. Viechtbauer W. Conducting meta-analyses in $\mathrm{R}$ with the metafor package. J Stat Softw. 2010;36(3):1-48.

20. RCoreTeam. R:A Language and Environment for Statistical Computing. Vienna: R Foundation for Statistical Computing; 2013. Available from: http:/www.R-project.org. Accessed May 5, 2013.

21. Berber A, Gómez-Santos R, Fanghänel G, Sánchez-Reyes L. Anthropometric indexes in the prediction of type 2 diabetes mellitus, hypertension and dyslipidaemia in a Mexican population. Int $J$ Obes Relat Metab Disord. 2001;25(12):1794-1799.

22. Craig P, Colagiuri S, Hussain Z, Palu T. Identifying cut-points in anthropometric indexes for predicting previously undiagnosed diabetes and cardiovascular risk factors in the Tongan population. Obes Res Clin Pract. 2007;1(1):17-25.

23. Dong X, Liu Y, Yang J, Sun Y, Chen L. Efficiency of anthropometric indicators of obesity for identifying cardiovascular risk factors in a Chinese population. Postgrad Med J. 2011;87(1026):251-256.

24. Ho SY, Lam TH, Janus ED. Hong Kong Cardiovascular Risk Factor Prevalence Study Steering Committee. Waist to stature ratio is more strongly associated with cardiovascular risk factors than other simple anthropometric indices. Ann Epidemiol. 2003;13(10):683-691.

25. Ko GT, Chan JC, Cockram CS, Woo J. Prediction of hypertension, diabetes, dyslipidaemia or albuminuria using simple anthropometric indexes in Hong Kong Chinese. Int J Obes Relat Metab Disord. 1999;23(11):1136-1142.

26. Li C, Ford ES, Zhao G, Kahn HS, Mokdad AH. Waist-to-thigh ratio and diabetes among US adults: The Third National Health and Nutrition Examination Survey. Diabetes Res Clin Pract. 2010;89(1):79-87.

27. Li M, McDermott R. Using anthropometric indices to predict cardiometabolic risk factors in Australian indigenous populations. Diabetes Res Clin Pract. 2010;87(3):401-406.

28. Li WC, Chen IC, Chang YC, Loke SS, Wang SH, Hsiao KY. Waist-to-height ratio, waist circumference, and body mass index as indices of cardiometabolic risk among 36,642 Taiwanese adults. Eur J Nutr. 2013;52(1):57-65.

29. Lin WY, Lee LT, Chen CY, et al. Optimal cut-off values for obesity: using simple anthropometric indices to predict cardiovascular risk factors in Taiwan. Int J Obes Relat Metab Disord. 2002;26(9):1232-1238.

30. Mansour AA, Al-Jazairi MI. Cut-off values for anthropometric variables that confer increased risk of type 2 diabetes mellitus and hypertension in Iraq. Arch Med Res. 2007;38(2):253-258. 
31. Park SH, Choi SJ, Lee KS, Park HY. Waist circumference and waistto-height ratio as predictors of cardiovascular disease risk in Korean adults. Circ J. 2009;73(9):1643-1650.

32. Pua YH, Ong PH. Anthropometric indices as screening tools for cardiovascular risk factors in Singaporean women. Asia Pac J Clin Nutr. 2005;14(1):74-79.

33. Schneider HJ, Glaesmer H, Klotsche J, et al. DETECT Study Group. Accuracy of anthropometric indicators of obesity to predict cardiovascular risk. J Clin Endocrinol Metab. 2007;92(2):589-594.

34. Tseng CH, Chong CK, Chan TT, et al. Optimal anthropometric factor cutoffs for hyperglycemia, hypertension and dyslipidemia for the Taiwanese population. Atherosclerosis. 2010;210(2):585-589.

35. Hsu HS, Liu CS, Pi-Sunyer FX, et al. The associations of different measurements of obesity with cardiovascular risk factors in Chinese. Eur J Clin Invest. 2011;41(4):393-404.

36. Deshmukh PR, Gupta SS, Dongre AR, et al. Relationship of anthropometric indicators with blood pressure levels in rural Wardha. Indian $J$ Med Res. 2006;123(5):657-664.

37. KhaderYS, Batieha A, Jaddou H, Batieha Z, El-Khateeb M, Ajlouni K. Anthropometric cutoff values for detecting metabolic abnormalities in Jordanian adults. Diabetes Metab Syndr Obes. 2010;3:395-402.

38. Rodrigues SL, Baldo MP, Mill JG. Association of waist-stature ratio with hypertension and metabolic syndrome: population-based study. Arq Bras Cardiol. 2010;95(2):186-191. English, Portuguese.

39. Silva DA, Petroski EL, Peres MA. Accuracy and measures of association of anthropometric indexes of obesity to identify the presence of hypertension in adults: a population-based study in Southern Brazil. Eur J Nutr. 2013;52(1):237-246.

40. Singh R, Mukherjee M, Kumar R, Singh R, Pal R. Study of risk factors of coronary heart disease in urban slums of Patna. Nepal Journal of Epidemiology. 2012;2(3):205-212.

41. Al-Odat AZ, Ahmad MN, Haddad FH. References of anthropometric indices of central obesity and metabolic syndrome in Jordanian men and women. Diabetes Metab Syndr. 2012;6(1):15-21.

42. He YH, Chen YC, Jiang GX, et al. Evaluation of anthropometric indices for metabolic syndrome in Chinese adults aged 40 years and over. Eur J Nutr. 2012;51(1):81-87.

43. Nakamura K, Nanri H, Hara M, et al. Optimal cutoff values of waist circumference and the discriminatory performance of other anthropometric indices to detect the clustering of cardiovascular risk factors for metabolic syndrome in Japanese men and women. Environ Health Prev Med. 2011;16(1):52-60.

44. Wakabayashi I, Daimon T. Receiver-operated characteristics (ROCs) of the relationships between obesity indices and multiple risk factors (MRFs) for atherosclerosis at different ages in men and women. Arch Gerontol Geriatr. 2012;55(1):96-100.

45. Chei CL, Iso H, Yamagishi K, et al. Body fat distribution and the risk of hypertension and diabetes among Japanese men and women. Hypertens Res. 2008;31(5):851-857.

46. Huerta JM, Tormo MJ, Chirlaque MD, et al. Risk of type 2 diabetes according to traditional and emerging anthropometric indices in Spain, a Mediterranean country with high prevalence of obesity: results from a large-scale prospective cohort study. BMC Endocr Disord. $2013 ; 13: 7$
47. Jia Z, Zhou Y, Liu X, et al. Comparison of different anthropometric measures as predictors of diabetes incidence in a Chinese population. Diabetes Res Clin Pract. 2011;92(2):265-271.

48. Sargeant LA, Bennett FI, Forrester TE, Cooper RS, Wilks RJ. Predicting incident diabetes in Jamaica: the role of anthropometry. Obes Res. 2002;10(8):792-798.

49. Xu F, Wang Y, Lu L, et al. Comparison of anthropometric indices of obesity in predicting subsequent risk of hyperglycemia among Chinese men and women in Mainland China. Asia Pac J Clin Nutr. 2010;19(4):586-593.

50. Aekplakorn W, Pakpeankitwatana V, Lee CM, et al. Abdominal obesity and coronary heart disease in Thai men. Obesity (Silver Spring). 2007;15(4):1036-1042.

51. Gelber RP, Gaziano JM, Orav EJ, Manson JE, Buring JE, Kurth T. Measures of obesity and cardiovascular risk among men and women. J Am Coll Cardiol. 2008;52(8):605-615.

52. Zhang X, Shu XO, Gao YT, Yang G, Li H, Zheng W. General and abdominal adiposity and risk of stroke in Chinese women. Stroke. 2009;40(4):1098-1104.

53. Petursson H, Sigurdsson JA, Bengtsson C, Nilsen TI, Getz L. Body configuration as a predictor of mortality: comparison of five anthropometric measures in a 12 year follow-up of the Norwegian HUNT 2 study. PLoS One. 2011;6(10):e26621.

54. Welborn TA, Dhaliwal SS. Preferred clinical measures of central obesity for predicting mortality. Eur J Clin Nutr. 2007;61(12):1373-1379.

55. Krakauer NY, Krakauer JC. A new body shape index predicts mortality hazard independently of body mass index. PLoS One. 2012;7(7): 39504

56. Cepeda-Valery B, Pressman GS, Figueredo VM, Romero-Corral A. Impact of obesity on total and cardiovascular mortality - fat or fiction? Nat Rev Cardiol. 2011;8(4):233-237.

57. Hsieh SD, Ashwell M, Muto T, Tsuji H, Arase Y, Murase T. Urgency of reassessment of role of obesity indices for metabolic risks. Metabolism. 2010;59(6):834-840.

58. Schneider HJ, Klotsche J, Silber S, Stalla GK, Wittchen HU. Measuring abdominal obesity: effects of height on distribution of cardiometabolic risk factors risk using waist circumference and waist-to-height ratio. Diabetes Care. 2011;34(1):e7.

59. Ashwell M, Gibson S. Waist to height ratio is a simple and effective obesity screening tool for cardiovascular risk factors: analysis of data from the British National Diet And Nutrition Survey of adults aged 19-64 years. Obes Facts. 2009;2(2):97-103.

60. Kagawa M, Byrne NM, Hills AP. Comparison of body fat estimation using waist:height ratio using different 'waist' measurements in Australian adults. Br J Nutr. 2008;100(5):1135-1141.

61. Ashwell M, Browning LM. The increasing importance of waist-to-height ratio to assess cardiometabolic risk: a plea for consistent terminology. Open Obes J. 2011;3:70-77. 


\section{Supplementary tables}

Table SI Quality assessment of prospective studies based on the Newcastle-Ottawa scale

\begin{tabular}{|c|c|c|c|c|c|c|c|c|c|c|}
\hline \multirow[t]{2}{*}{ Prospective study } & \multicolumn{4}{|c|}{ Selection } & \multicolumn{2}{|c|}{ Comparability } & \multicolumn{3}{|c|}{ Outcome } & \multirow[t]{2}{*}{ Total stars } \\
\hline & I & 2 & 3 & 4 & 5 & 6 & 7 & 8 & 9 & \\
\hline Aekplakorn et al ${ }^{50}$ & $*$ & $*$ & $*$ & - & $*$ & - & $*$ & $*$ & $*$ & 7 \\
\hline Chei et $\mathrm{al}^{45}$ & $*$ & $*$ & $*$ & $*$ & $*$ & $*$ & $*$ & $*$ & - & 8 \\
\hline Gelber et $\mathrm{al}^{51}$ & - & $*$ & $*$ & $*$ & $*$ & - & $*$ & - & - & 5 \\
\hline Huerta et $\mathrm{al}^{46}$ & $*$ & * & $*$ & * & $*$ & - & * & - & - & 6 \\
\hline Jia et $\mathrm{al}^{47}$ & $*$ & * & $*$ & $*$ & $*$ & $*$ & $*$ & - & $*$ & 8 \\
\hline Petursson et $\mathrm{a}^{53}$ & - & $*$ & $*$ & * & $*$ & $*$ & $*$ & $*$ & $*$ & 8 \\
\hline Sargeant et $\mathrm{al}^{48}$ & - & $*$ & - & $*$ & $*$ & $*$ & $*$ & $*$ & $*$ & 7 \\
\hline Welborn and Dhaliwal ${ }^{54}$ & $*$ & * & $*$ & $*$ & $*$ & - & $*$ & $*$ & $*$ & 8 \\
\hline Xu et $\mathrm{al}^{49}$ & $*$ & * & $*$ & $*$ & $*$ & - & $*$ & $*$ & $*$ & 8 \\
\hline Zhang et $\mathrm{al}^{52}$ & $*$ & $*$ & $*$ & $*$ & $*$ & - & * & $*$ & - & 7 \\
\hline
\end{tabular}

Notes: I: Representativeness of the exposed cohort; 2: selection of the non-exposed cohort; 3: ascertainment of exposure; 4: demonstration that outcome of interest was not present at start of study; 5: comparability of cohorts on the basis of the design or analysis; 6: comparability of cohorts on the basis of the design or analysis; 7 : assessment of outcome; 8: was follow-up long enough for outcomes to occur; 9: adequacy of follow-up of cohorts. More information available from: http://www.ohri.ca/programs/ clinical_epidemiology/oxford.asp..$^{17}$

Table S2 Quality assessment of cross-sectional studies

\begin{tabular}{|c|c|c|c|c|c|c|}
\hline Cross-sectional study & $\begin{array}{l}\text { Representative } \\
\text { sample }\end{array}$ & $\begin{array}{l}\text { Ascertainment } \\
\text { of exposure }\end{array}$ & $\begin{array}{l}\text { Selective } \\
\text { reporting }\end{array}$ & $\begin{array}{l}\text { Incomplete } \\
\text { outcome data }\end{array}$ & $\begin{array}{l}\text { Assessment } \\
\text { of outcome }\end{array}$ & $\begin{array}{l}\text { Total score } \\
\text { (maximum 5) }\end{array}$ \\
\hline Al-Odat et $\mathrm{al}^{40}$ & - & $*$ & $*$ & $*$ & $*$ & 4 \\
\hline Berber et $\mathrm{al}^{21}$ & - & $*$ & $*$ & - & $*$ & 3 \\
\hline Craig et $\mathrm{al}^{22}$ & $*$ & $*$ & $*$ & $*$ & $*$ & 5 \\
\hline Deshmukh et $\mathrm{a}^{36}$ & $*$ & $*$ & $*$ & - & $*$ & 4 \\
\hline Dong et $\mathrm{a}^{23}$ & $*$ & $*$ & $*$ & $*$ & $*$ & 5 \\
\hline He et $\mathrm{al}^{42}$ & - & $*$ & $*$ & $*$ & $*$ & 4 \\
\hline Ho et $\mathrm{a}^{24}$ & - & $*$ & $*$ & $*$ & $*$ & 4 \\
\hline Hsu et $\mathrm{a}^{35}$ & $*$ & $*$ & $*$ & $*$ & $*$ & 5 \\
\hline Khader et $\mathrm{al}^{37}$ & $*$ & * & * & * & $*$ & 5 \\
\hline Ko et $\mathrm{al}^{25}$ & - & $*$ & $*$ & $*$ & $*$ & 4 \\
\hline Li et $\mathrm{al}^{26}$ & $*$ & $*$ & $*$ & $*$ & $*$ & 5 \\
\hline $\mathrm{Li}$ and $\mathrm{McDermott}{ }^{27}$ & - & $*$ & $*$ & $*$ & $*$ & 4 \\
\hline $\mathrm{Li}$ et $\mathrm{a}^{28}$ & - & $*$ & * & $*$ & $*$ & 4 \\
\hline Lin et $\mathrm{al}^{29}$ & - & * & * & * & $*$ & 4 \\
\hline Mansour and $\mathrm{Al}$-Jazairi ${ }^{30}$ & $*$ & $*$ & $*$ & $*$ & $*$ & 5 \\
\hline Nakamura et $\mathrm{a}^{43}$ & - & $*$ & $*$ & $*$ & $*$ & 4 \\
\hline Park et $\mathrm{a}^{31}$ & - & * & * & $*$ & $*$ & 4 \\
\hline Pua and Ong ${ }^{32}$ & - & $*$ & $*$ & $*$ & $*$ & 4 \\
\hline Rodrigues et a ${ }^{38}$ & - & $*$ & $*$ & $*$ & $*$ & 4 \\
\hline Schneider et $\mathrm{al}^{33}$ & - & * & * & $*$ & $*$ & 4 \\
\hline Silva et $\mathrm{a}^{39}$ & $*$ & $*$ & $*$ & $*$ & $*$ & 5 \\
\hline Singh et $\mathrm{al}^{40}$ & - & * & * & $*$ & * & 4 \\
\hline Tseng et $\mathrm{al}^{34}$ & - & * & * & - & * & 3 \\
\hline Wakabayashi and Daimon ${ }^{44}$ & - & $*$ & $*$ & $*$ & $*$ & 4 \\
\hline
\end{tabular}


Table S3 Random effects meta-regression analysis for cross-sectional studies using predefined study covariates

\begin{tabular}{llllll}
\hline & \multicolumn{2}{l}{ Estimated coefficients $(\mathbf{9 5 \%} \mathbf{~ C l}) *$ for covariates used in multivariable meta-regression analysis } \\
\cline { 2 - 6 } & Origin & Sex & Optimal BMI cutoff & Optimal WHtR cutoff & $\begin{array}{l}\text { Interaction term } \\
\text { origin } \times \text { sex }\end{array}$ \\
\hline Diabetes mellitus & $0.33(-3.69,4.70)$ & $0.17(-0.34,0.68)$ & $0.05(-0.10,0.21)$ & $-4.63(-16.54,7.28)$ & $-0.07(-0.84,0.70)$ \\
Dyslipidemia & $0.55(-0.05,1.16)$ & $0.10(-0.24,0.44)$ & $0.03(-0.19,0.24)$ & $-4.20(-12.09,3.69)$ & $-0.08(-0.69,0.53)$ \\
Elevated blood pressure & $0.28(-0.18,0.74)$ & $-0.01(-0.43,0.42)$ & $-0.01(-0.12,0.12)$ & $-1.42(-7.59,4.75)$ & $-0.02(-0.75,0.70)$ \\
Metabolic syndrome & $0.01(-0.29,0.29)$ & $0.05(-0.08,0.18)$ & $-0.03(-0.10,0.04)$ & $1.66(-2.36,5.69)$ & $-0.02(-0.31,0.27)$ \\
\hline
\end{tabular}

Note: *None of the estimated coefficients reached statistical significance (all $P>0.05$ ).

Abbreviations: $\mathrm{BMI}$, body mass index; $\mathrm{Cl}$, confidence interval; $\mathrm{WHtR}$, waist-to-height ratio.

\section{Publish your work in this journal}

Diabetes, Metabolic Syndrome and Obesity: Targets and Therapy is an international, peer-reviewed open-access journal committed to the rapid publication of the latest laboratory and clinical findings in the fields of diabetes, metabolic syndrome and obesity research. Original research, review, case reports, hypothesis formation, expert opinion and commentaries are all considered for publication. The manuscript management system is completely online and includes a very quick and fair peer-review system, which is all easy to use. Visit http://www.dovepress.com/testimonials.php to read real quotes from published authors.

Submit your manuscript here: http://www.dovepress.com/diabetes-metabolic-syndrome-and-obesity-targets-and-therapy-journal 